University of Massachusetts Amherst

ScholarWorks@UMass Amherst

Communication Department Faculty Publication

Series

Communication

2011

\title{
The Friendly Media Phenomenon: A Cross-National Analysis of Cross-Cutting Exposure
}

Seth K. Goldman

University of Massachusetts - Amherst

Diana C. Mutz

Follow this and additional works at: https://scholarworks.umass.edu/communication_faculty_pubs

\section{Recommended Citation}

Goldman, Seth K. and Mutz, Diana C., "The Friendly Media Phenomenon: A Cross-National Analysis of Cross-Cutting Exposure" (2011). Political Communication. 105.

https://doi.org/10.1080/10584609.2010.544280

This Article is brought to you for free and open access by the Communication at ScholarWorks@UMass Amherst. It has been accepted for inclusion in Communication Department Faculty Publication Series by an authorized administrator of ScholarWorks@UMass Amherst. For more information, please contact scholarworks@library.umass.edu. 


\title{
The Friendly Media Phenomenon: A Cross-National Analysis of Cross-Cutting Exposure
}

\author{
SETH K. GOLDMAN and DIANA C. MUTZ
}

\begin{abstract}
We hypothesize that in the real world, as opposed to the lab, the norm is for people to experience friendly media that favor their political predispositions when political favoritism is perceived at all. For this reason, media are generally limited in their ability to create cross-cutting exposure. We test this hypothesis using representative survey data drawn from 11 different countries with varying media systems. We further hypothesize that television will contribute more to cross-cutting exposure than newspapers. Finally, and most importantly, we test the hypothesis that the more the structure of a country's media system parallels that of its political parties, the more that country's population will be dominated by exposure to like-minded views via mass media. We find confirmation for all 3 of these hypotheses and discuss their implications for the role of mass media in providing exposure to cross-cutting political perspectives.
\end{abstract}

Keywords hostile media, selective exposure, cross-cutting exposure, political communication, media systems

Cross-cutting exposure means that people must be exposed to political perspectives that they do not find agreeable. Some suggest that mass media are a key conduit for these viewpoints to reach citizens. So how, on the whole, do citizens feel about the political perspectives in the newspapers and television programs that deliver their news? Not very positively, according to the most prominent theory bearing on this question in the academic literature. The "hostile media phenomenon" suggests that "a large percentage of the public believes that the news media are biased, and the majority of these individuals consider the direction of bias to be against their own viewpoint" (see Eveland \& Shah, 2003, p. 101).

Based on this theory, one might assume that cross-cutting exposure is considerable. However, a second prominent theory implies precisely the opposite. To the extent that theories of selective exposure are correct, people should be exposing themselves to like-minded media to whatever extent possible. To date, both theories boast considerable empirical support, but the seeming inconsistencies have not been addressed.

In this study we resolve these apparent inconsistencies, using data from 11 countries to illustrate why the "friendly media phenomenon" is the most appropriate overall description of the way in which citizens relate to the partisanship of their news sources outside of experimental settings. Using cross-national variation in media systems, we examine the

Seth K. Goldman is a post-doctoral research fellow in the Annenberg School for Communication at the University of Pennsylvania. Diana C. Mutz is the Samuel A. Stouffer Professor of Communication and Political Science at the University of Pennsylvania.

Address correspondence to Seth K. Goldman, University of Pennsylvania, Annenberg School for Communication, 3620 Walnut Street, Philadelphia, PA 19104-6220, USA. E-mail: sgoldman@asc.upenn.edu 
extent to which media are perceived as hostile to their readers' or viewers' political interests and/or facilitate selective exposure to like-minded views. Although selective exposure has been widely examined at the individual level, ultimately what is of value to any given political culture is the extent to which its media system exposes sizable proportions of its population to cross-cutting views. By using countries in addition to individuals as units of analysis, we evaluate the effects of national media environments on their citizenries.

In addition, we examine the effects of "media-party parallelism" for cross-cutting exposure, that is, the effects of environments in which the structure of the media system parallels the structure of the political parties of their readers or viewers. In particular, we use cross-national variance in media-party parallelism to test the hypothesis that high levels of media-party parallelism will result in less cross-cutting exposure. To the extent that certain newspapers or television programs are associated with partisans of various kinds, self-selection is facilitated, and thus citizens will ultimately experience less cross-cutting exposure via mass media. Indeed, we argue that newspapers expose their readers to fewer cross-cutting political ideas than television news programs, precisely because newspaper environments exhibit significantly more media-party parallelism.

Exposure to cross-cutting political ideas is widely accepted as a necessary component of a healthy public sphere. As Calhoun (1988) has argued, "In modern societies, most of the information we have about members of other communities, and in general about people different from ourselves, comes not through any direct relationships, even the casual ones formed constantly in urban streets and shops. Rather, it comes through print and electronic media" (p. 255). Within the United States, people come into contact with political views that differ from their own more often through mass media than through personal networks (Mutz \& Martin, 2001). To be sure, newspapers and television news cannot provide the interactivity provided by interpersonal encounters; however, they still constitute important sources of exposure to political views. Moreover, the theory behind the public sphere is about people listening to one another across lines of difference as much as speaking across lines of difference (Barber, 1984; Young, 1996), and few would dispute media's importance in this regard.

\section{The Hostile Media Phenomenon}

The hostile media phenomenon refers to situations in which partisans on opposite sides of a controversy perceive the same media content to be favorable toward opposing sides, and thus biased against their own viewpoints (Vallone, Ross, \& Lepper, 1985). What is fascinating about this theory is that it defies reality: Obviously, both sides cannot be correct that the same content is biased in opposite directions. Clearly, then, judgments of media "bias" must emanate from characteristics of those judging the content instead of, or in addition to, the content itself.

In order to provide evidence of the hostile media phenomenon, controlled experiments have been used to establish that (a) partisans are, in fact, judging the same content; (b) the two sides differ in their perceptions of the extent and direction of partisan bias; and (c) most partisans on both sides perceive the content as hostile to their own side. Understandably, observational studies have a more difficult time establishing the first criterion because outside of an experiment, it is difficult to be sure that two groups are judging the same media content. If a Democrat reads one newspaper and sees it as favoring Republicans, whereas a Republican reads a completely different newspaper and claims it favors Democrats, 
researchers cannot be certain that partisans are incorrect and that perceptual biases are at work.

In observational studies, respondents are generally asked in more general terms about newspaper coverage or television coverage of some issue (without indicating a specific source), or perhaps about coverage in their "most frequently read" newspaper (see Gunther, 1992). In either case, respondents are not necessarily judging the same media content when formulating their responses, thus making it difficult to argue that this is evidence of a hostile media phenomenon. In the real world, many partisans on opposite ends of the political spectrum do not read and view exactly the same media content.

Thus, the hostile media phenomenon defies easy examination outside of the lab. However, the term "relative hostile media perception" refers to situations in which one group of partisans holds a different perception of the extent of bias from the other group, regardless of whether those perceptions indicate hostility toward one's own views (Gunther $\&$ Christen, 2002). This relative perception is of equal interest from a psychological perspective when people are judging identical sources, because the discrepancy still begs for an explanation. But from the perspective of cross-cutting exposure, it is less relevant because a relatively more hostile perception of favoritism on the part of a media source may, in reality, just be a relatively less friendly perception that is nonetheless still supportive of the reader or viewer's political perspective.

Importantly, the relative perception is what has been documented most often in observational studies dubbed hostile media effects (see, e.g., Dalton, Beck, \& Huckfeldt, 1998). A relative hostile media perception does not require that people on both sides perceive the media as hostile to their own interests, only that perceptions of the level or extent of favoritism be different across the two groups. So, for example, in the Dalton et al. (1998) study, evidence of a hostile media effect is based on a significant coefficient $(b=-.04)$ for individual party identification in predicting perceived favoritism in newspapers. Republicans were more likely to see their newspaper as favoring Clinton than were strong Democrats. However, the majority of people who perceived favoritism toward one side or the other in their source perceived it as in the direction supporting their own views rather than opposing them.

It is possible, then, for people to judge content to be primarily neutral or like-minded, yet still believe that it is less favorable toward their own side than the other, opposing political group might think. In other words, evidence consistent with selective exposure and low levels of cross-cutting exposure is possible along with the relative hostile media perception, although it could not occur with the hostile media phenomenon as originally defined. Put another way, a relative hostile media perception is not prima facie evidence for high levels of cross-cutting exposure.

\section{Selective Exposure}

Selection of media sources on the basis of like-minded political views is a central concern of our study because of its obvious implications for the extent of cross-cutting exposure. Although selective exposure is an old topic in the study of political communication (see, e.g., Lazarfeld, Berelson, \& Gaudet, 1944), it has grown in notoriety and interest in recent years because the proliferation of channels and choices makes selection processes all the more likely and necessary (see, e.g., Iyengar, Hahn, Krosnick, \& Walker, 2008).

Nevertheless, evidence for selective exposure with respect to mass media has been mixed at best (Cotton, 1985; Frey, 1986; Sears \& Freedman, 1967). It remains unclear why 
some studies find significant effects (e.g., Iyengar \& Hahn, 2009; Iyengar et al., 2008), while others do not (e.g., Meffert, Chung, Joiner, Waks, \& Garst, 2006). Moreover, because the vast majority of studies are laboratory experiments, their findings may not be generalizable to more naturalistic settings where people may or may not have choices that reflect a range of political views, and where media choices may be largely habitual and long term rather than on a story-by-story or day-by-day basis (Cotton, 1985; Frey, 1986; Mutz \& Martin, 2001).

Despite general interest in exposure to cross-cutting political ideas, few empirical studies speak to the role of media in facilitating or limiting exposure to like-minded views. Within the U.S., those citizens with a choice of local newspaper are exposed to less crosscutting exposure than those without a choice (Mutz \& Martin, 2001), thus suggesting that choice leads to less cross-cutting exposure. For these reasons, we predict a pattern of friendly, politically consonant media exposure in our study, to the extent that favoritism is perceived at all in a given medium. If patterns of face-to-face interaction tell us anything about human behavior, it is that people gravitate toward like-minded others, and we expect the pattern for mass media to reflect that same impulse.

\section{Contrasting Television and Newspapers}

Descriptions of "television as a common ground" have been contrasted with "traditions of partisan commentary common in the print press" (Hallin \& Mancini, 2004, p. 270). Television news originated as "catchall media, capable of delivering messages across ideological and group boundaries" (Hallin \& Mancini, 2004, p. 270), while newspapers began as highly partisan information sources. For these reasons, we further hypothesize that television news generally provides higher levels of exposure to dissimilar views than newspapers.

In America's early years, newspapers were highly partisan, but as of the 1990s the vast majority of both newspapers and television news programs aimed to provide nonpartisan political coverage (Schudson, 1981). In Europe, although many print journalists now claim to be nonpartisan, in practice a great deal of partisan coverage remains according to some scholars (Hallin \& Mancini, 2004). These differing traditions help to explain the lower levels of exposure to dissimilar views from newspapers in Britain than in the U.S. (Mutz \& Martin, 2001). Partisan reputations facilitate selective exposure and thus thwart cross-cutting exposure. In addition, in Europe the partisanship of newspaper readers is more closely tied to the readers' party loyalties than are the party loyalties of viewers of television programs, suggesting that television will better facilitate cross-cutting exposure (van Kempen, 2007).

Because of the large viewership and "catchall" nature of television, we predict that television will provide more exposure to cross-cutting views than newspapers, the latter of which should more easily facilitate selective exposure. However, owing to growing audience fragmentation in television, on the one hand, and movement toward less partisan newspaper coverage, on the other, the difference in levels of cross-cutting exposure between these media is likely to be modest.

\section{Media-Party Parallelism}

When patterns of exposure to specific media sources parallel the party structure, a country is said to have a higher degree of "media-party parallelism" (Seymour-Ure, 1974; van Kempen, 2007). This concept reflects the extent to which individual political allegiances 
correspond with the partisanship of people's news sources. Parallelism need not be formal, as in a newspaper that is directly owned by a political party or aligned with a specific ideology, but parallelism should be reflected in ongoing aggregate patterns of media use and partisanship.

Conceptually, media-party parallelism is not identical to partisanship in media, though they may be closely related. Because partisan sources can exist without audiences that are similarly segregated by partisanship, the two may not always go hand in hand. For example, van Kempen (2007) points to Germany as an example of where newspapers with ideological reputations are only very weakly associated with the political characteristics of their readership. Based on Seymour-Ure's (1974) concept of press-party parallelism, van Kempen operationalized media-party parallelism as the extent to which the use of specific media sources predicted specific types of partisanship (see van Kempen, 2007, pp. 319-320, for details). She found that countries with higher levels of parallelism tended to have significantly higher turnout than those with lower levels of media-party parallelism, thus suggesting that like-minded media play an important role in mobilization. Interestingly, this result is consistent with results from social network studies where exposure to like-minded networks increases an individual's likelihood of turnout, whereas cross-cutting exposure dampens it (see Mutz, 2006).

Countries vary a great deal in the extent to which their media are structured by parties. And although diverse media with strong differences of political opinion might best approximate the "marketplace of ideas" that John Stuart Mill (1859/1956) and others promoted, media-party parallelism may function to promote homogeneity of exposure at the individual level. If one lives in an environment with many media outlets of many different political stripes, one is especially likely to find a news source that is politically congenial, regardless of how moderate or extreme one's views might be. On the other hand, in a media environment with few choices and/or choices with muted partisanship, it is unlikely that one will succeed in finding a source that allows avoidance of crosscutting views. Overall, then, we predict that higher levels of media-party parallelism in a country's media will go hand in hand with lower levels of exposure to cross-cutting views.

To examine the three hypotheses that we have proposed, we draw on data from representative national telephone surveys conducted in the 1990s in 11 different countries under the auspices of the Cross-National Election Project (CNEP). To review, we hypothesize that (a) across countries, both television and newspapers will provide more like-minded than cross-cutting exposure; (b) television will generally provide more cross-cutting exposure than newspapers; and (c) the extent of media-party parallelism in a country will be negatively related to the extent of cross-cutting exposure its citizens experience.

\section{Methods}

In order to examine these hypotheses, we draw on data from representative national telephone surveys conducted in 11 countries. The countries included are Bulgaria, Chile, Greece, Hungary, Hong Kong, Italy, Japan, the United Kingdom, Spain, Uruguay, and the U.S. All 11 surveys were carried out during the 1990s and included sample sizes ranging from 966 to 3,534 (see Appendix A for details). To examine our hypotheses, we require (a) measures of individual media use; (b) information on the perceived favoritism of each source, including television news and newspapers, as well as the respondents' own preferences in order to estimate exposure to cross-cutting views; and (c) indicators of media-party parallelism (see Appendix B for wording of survey items). 


\section{Media Use}

Because surveys across the countries varied in how many different media sources were asked about, we used the most frequently read newspaper and most frequently watched television news program to facilitate comparisons. As is commonly problematic in crossnational research, the more detailed scales for frequency of media use in the CNEP surveys are too vague in terminology and translation and too irregular across countries to facilitate comparisons. For example, in some countries, the questions asked in an open-ended format how many days a week respondents watched a television news program or read a newspaper. In other countries, the questions utilized closed-ended response options (e.g., every day, 4-5 days a week, 2-3 days a week, 1 day a week or less). Because of these discrepancies and the need for comparisons, we assessed media use as dichotomized indicators for each medium in all 11 countries.

\section{Perceived Favoritism and Cross-Cutting Exposure}

In order to operationalize cross-cutting exposure, we need to know the respondents' political position and the political position they perceive their media source to favor. Operationalizing this concept using partisanship is inherently problematic in cross-national studies. Although our first inclination was to use party identification, American versions of these measures have not crossed national borders easily (e.g., Blais, Gidengil, Nadeau, \& Nevitte, 2001; Johnston, 2006). In addition, using party identification as the basis for comparison, much of the sample would be lost from countries where few people claim "identification" with a particular party. Moreover, in constructing these measures it was desirable to develop ones that would work equally well with two-party and multiparty systems.

In complex multiparty systems, some with rapidly changing coalitions, it would be a mistake to assume that a media source favoring a party that is different from the respondent's party necessarily represents exposure to a disagreeable viewpoint. The two could be from closely aligned parties and thus perceive their interests to be quite similar. Likewise, a newspaper could favor one liberal party, while the respondent favored a different liberal party. In that case, the fact that the newspaper did not favor the respondent's own party would not necessarily indicate exposure to disagreeable political views.

To circumvent these issues, we used both indicators of which party (or candidate of which party) the news source favored and indicators of how close the respondent perceived that particular party to be to his or her own position. By combining these two items, we were able to construct measures of the extent to which the views favored by news sources were considered "very close," "somewhat close," "somewhat distant," or "very distant" from the respondent's own political views. As shown in Appendix A, for six of the 11 countries, identical 4-point party proximity scales were available for these purposes. Of the remaining five countries, three utilized 10-point favorability scales (Hong Kong, Japan, and the U.S.), and the U.K. used a 5-point favorability scale. For all of these scales, readers/viewers who did not perceive any political favoritism in a media source were placed at the midpoint of the scales, indicating that they felt neither close to nor distant from the source.

A second approach to this same problem that worked for a subset of the countries compared the left-right self-placements of respondents with the left-right placements of parties to determine whether they leaned in the same or opposite directions. Thus, for each media source, we obtained a measure of whether the source leaned in the same direction as the respondent or the opposing direction. Because these indicators are based on a 
combination of three survey questions rather than two, they also tended to produce more missing data. For this reason, the party-based proximity measures were used for all of the countries except Italy, which had no indicators of attitudes toward the parties, and here left-right comparisons were substituted.

It is worth noting that the measures that we created for perceived partisanship have at times been used by others as indicators of political bias when ascribed to mass media. The measures that we use are not meant to connote a deviation from an accurate portrayal of political reality. As the hostile media finding aptly illustrates, the subjectivity of human perception makes this assertion inevitably difficult, and the usual solution to this problemcontent analysis - is rife with its own epistemological problems. Although content analyses of media coverage can be extremely valuable for some purposes, coders are subject to the same subjectivity problems as are others when judging the positivity or negativity of content. While we agree that some media sources exhibit greater favoritism toward a political party or viewpoint than do others, relying on the perceptions of coders makes little sense if one believes that coding agreement may be simply a function of political similarity among coders. Without any exception we know of, previous studies have not obtained a consensus on favoritism within news sources using ideologically opposed coders.

If a study requires cross-national measures of partisan favoritism, one must add to these epistemological difficulties the complications of coding media content crossnationally, which would require coders from all political parties within each country. Such an approach would obviously be impractical. For this reason, some have suggested using indicators such as the partisanship of the owner of the newspaper or television station, editorial endorsements, or general knowledge of what kind of political views a media source is "known" to support. Unfortunately, there is no systematically gathered information of this kind across these countries' media. Moreover, there is no academic agreement as to which sources are more or less partisan and in what direction, although some agreement exists at the level of specific pairs (e.g., that newspapers in Britain tend to be more partisan than those in the U.S.).

Finally, and perhaps most importantly, we rely on perceived disagreement in media because we expect cross-cutting exposure to benefit readers and viewers only insofar as they are able to recognize it as such. In other words, even if objective measures of source partisanship could be obtained, it is not clear that they would be superior measures for purposes of what we seek to study. Cross-cutting exposure can do little good if it is sufficiently subtle that readers and viewers do not recognize it. For all of these reasons, we define crosscutting exposure as when the perceived political leaning of the source is distant from the political leaning reported by the respondent. Perceived political favoritism may or may not indicate a biased account of political events, but it clearly indicates that people have been exposed to arguments they perceive to favor a particular side over their own. ${ }^{1}$ By aggregating perceived favoritism at the level of whole countries, we also created measures of the direction of perceived partisanship for each country. Positive numbers indicate that the majority perceived partisanship in the direction of citizens' own views, whereas negative scores indicate that the majority of partisanship is perceived to be in the opposing, more hostile direction, and scores near zero indicate equal numbers of each.

\section{Media-Party Parallelism}

In addition to assessing media use and the perceived favoritism of sources, we also created a system-level measure to tap the extent to which media use and political predispositions in a given country are organized along parallel lines. To measure this construct, 
we use the same technique described at length in van Kempen's (2007) cross-national study, evaluating the extent to which indicators of closeness to the various parties can be predicted by use of specific media sources. A series of regression equations was used to estimate closeness to each major party using dummy variables for use of specific sources as predictor variables (see van Kempen, 2007, pp. 319-320). The adjusted $R^{2}$ values predicted by these equations were then weighted by the size of the political parties (to prevent strong relationships for very small portions of the population from unduly skewing the estimates) and combined into a single aggregate indicator for each country. ${ }^{2}$ By assessing this relationship, we are not asserting causality in any given direction. Instead, we seek to characterize in the aggregate the extent to which partisan affinities are related to patterns of media use. A high score on media-party parallelism indicates a high degree of concordance, whereas a relatively low score indicates that little about individual partisan affinities accords with patterns of media use. ${ }^{3}$ Although we utilize survey data to create these measures, they are not based on perceptions of media favoritism as are our measures of cross-cutting exposure. Instead, they provide aggregate measures of the structure of each country's media system relative to its party system.

Take, for example, the measurement of press-party parallelism in Greece: Respondents were asked if they followed campaign news through newspapers and, if so, which newspaper they read most often. We created dummy variables for each of the 24 newspapers listed by respondents. We then entered those 24 dummy variables into six separate regression equations, with each one predicting closeness toward one of the six political parties asked about in the survey. The adjusted $R^{2}$ value for each party was multiplied by its vote share in the 1996 election, producing weighted $R^{2}$ s. Finally, the sum of the six weighted $R^{2}$ s was divided by the sum of the vote shares of the six parties and multiplied by 100 . These final two steps ensured that the measure of press-party parallelism (a) accounted for the total coverage of the parties asked about on the survey, in this case covering $98 \%$ of the sample, and (b) had a theoretical range of 0 to 100.

\section{Results: A Friendly or Hostile Medium?}

Do citizens perceive newspapers and television news as exposing them to primarily disagreeable political content, as predicted by the hostile media phenomenon? Or do citizens perceive their media as exposing them to like-minded political content, as predicted by theories of selective exposure? To arbitrate between these competing possibilities, we begin with Figure 1, which shows the total percentage of newspaper readers in each country perceiving partisanship in either direction across the $x$-axis and the extent to which the source leans, on balance, toward or away from respondents' own views on the $y$-axis. Zero on the $y$-axis represents the case in which equal percentages of respondents see the source as favoring their own views and favoring oppositional views; positive scores indicate that a greater number of respondents perceive the source as favoring their own views, and negative scores indicate that, on balance, newspaper leanings are inconsistent with respondents' political views.

The first and most obvious thing to note in Figure 1 is that all of the values on the $y$-axis are 0 or greater. On the whole, if people's newspapers lean in any political direction, it tends to be in the direction of their own views. Put another way, Figure 1 shows a strong positive relationship between the extent of perceived partisanship in a country's newspapers and the extent to which political views encountered via newspapers are like-minded $(r=.81$, $p<.01$ ). The pattern for newspapers is clearly toward regular use of a friendly, rather than a hostile, medium, at least when considering the newspaper respondents read most often. 


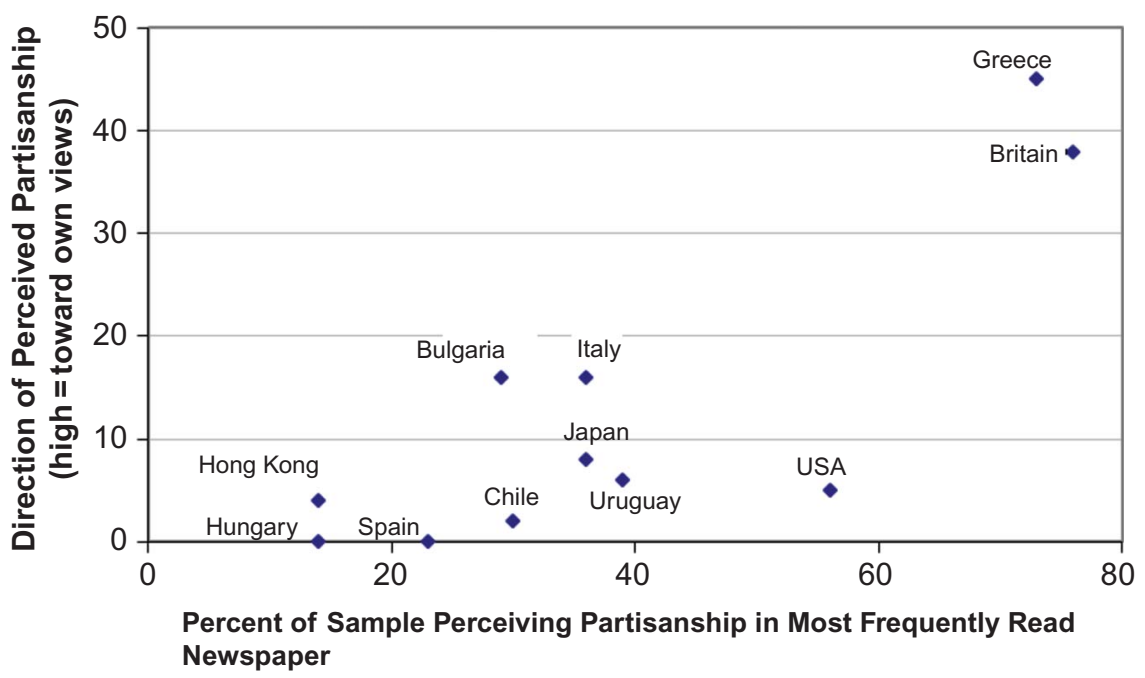

Figure 1. Relationship between extent and direction of partisanship for most frequently read newspaper.

Figure 2 shows the same scales as Figure 1 but plots the data for television news by country. Unlike Figure 1, some countries do, in fact, fall below zero on the $y$-axis in Figure 2, but for the most part countries are tightly clustered around zero, indicating little perceived partisanship in either direction on average. The values on the $x$-axis

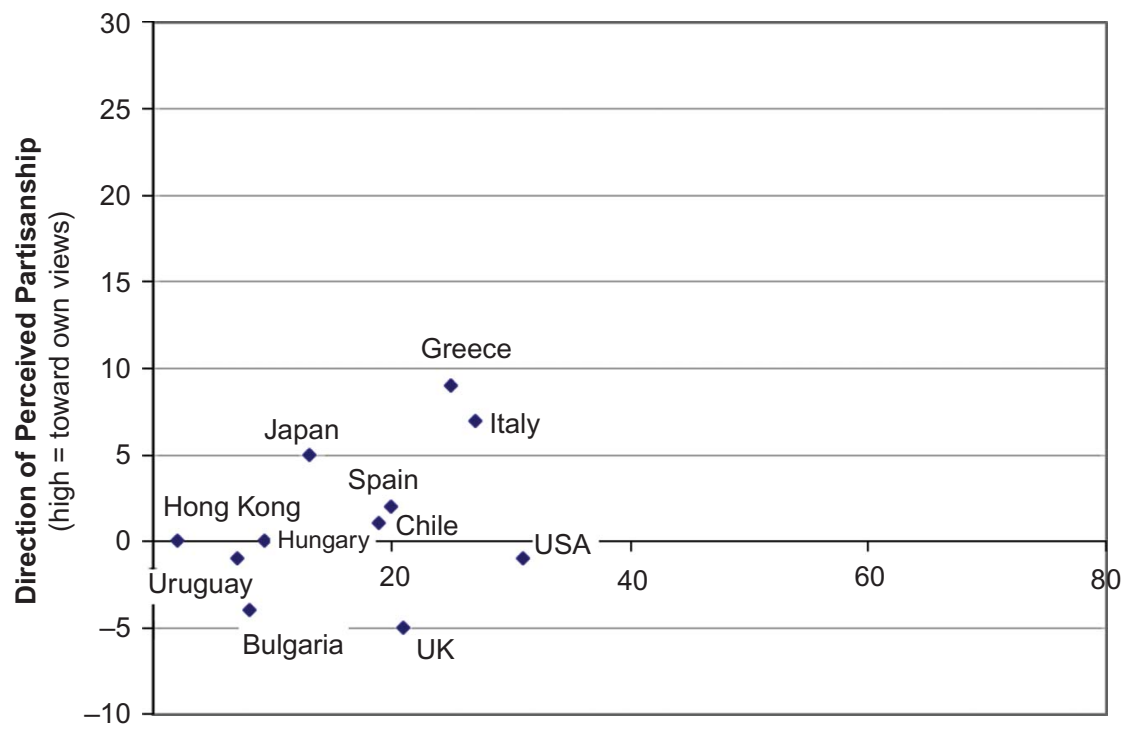

Percent of Sample Perceiving Partisanship in Most Frequently Watched TV News

Figure 2. Relationship between extent and direction of partisanship for most frequently watched TV news. 
are likewise truncated into a much lower range, suggesting that smaller percentages perceive any partisanship at all in this medium. Unlike the pattern observed in Figure 1, the relationship shown in Figure 2 is not significant $(r=.26, p=.48)$.

Taken together, these findings undercut the predictions of the hostile media phenomenon. Among newspaper readers who did perceive partisanship, most reported exposure to like-minded political views. Television news viewers, meanwhile, did not perceive much partisanship at all, in either direction. Thus, the patterns observed here suggest that hostile media perceptions are few and far between in the real world.

\section{Comparing Cross-Cutting Exposure in Television News and Newspapers}

Does television news provide greater exposure to cross-cutting political views than newspapers? The results from Figures 1 and 2 point to television as the more likely purveyor of exposure to opposing political ideas, but to provide more rigorous tests we make within-country and within-person comparisons using the full range of proximity scores. Table 1 presents the average levels of cross-cutting exposure of respondents' most frequently watched television news program (column 1) and most frequently read newspaper (column 2) within each country. Column 3 in Table 1 provides the difference, that is, the average level of cross-cutting exposure from television news minus the average level of cross-cutting exposure from newspapers. As shown by the positive values in column 3 , in 10 of the 11 countries, these differences were in the expected direction, indicating that television news typically provides more cross-cutting exposure than newspapers. Only Chile shows a negative value, though this difference was not statistically significant.

In six of the countries, independent-samples $t$ tests (column 4) confirmed that there were significantly higher levels of cross-cutting exposure from television news than from newspapers $(p<.05)$, and a seventh country showed a marginally significant difference $(p<.10)$. To ensure that these differences could not be explained purely by varying demographic characteristics between television viewers and newspaper readers, we also conducted paired $t$ tests (column 5) among the subset of respondents who reported watching television news and reading at least one newspaper. The results from the paired $t$ tests provide even stronger evidence for our hypothesis than the initial findings. The paired $t$ tests revealed significantly higher levels of cross-cutting exposure from television news than newspapers in eight countries $(p<.05)$, and a ninth country showed a marginally significant difference $(p<.10){ }^{4}$

To be sure, neither television news nor newspapers provide particularly high levels of cross-cutting exposure. The values for both groups hover around the midpoint of the scales, meaning that on average most people are exposed to either neutral content or equal amounts of exposure to like-minded and dissimilar political views. Where we do find significant differences in the extent of exposure to dissimilar views between these media, they can be explained mostly by the especially low levels of cross-cutting exposure encountered via newspapers.

\section{Contextual Effects of Media-Party Parallelism}

We suggest that media environments that exhibit higher levels of media-party parallelism produce lower levels of cross-cutting exposure. If media use breaks along party lines, it is presumably because the available media sources offer more clearly defined political 
Table 1

Cross-cutting exposure in TV news and newspapers by country

\begin{tabular}{|c|c|c|c|c|c|}
\hline & $\begin{array}{c}\text { Most frequently } \\
\text { watched TV } \\
\text { news }\end{array}$ & $\begin{array}{l}\text { Most } \\
\text { frequently } \\
\text { read } \\
\text { newspaper }\end{array}$ & $\begin{array}{l}\text { TV minus } \\
\text { newspaper }\end{array}$ & $\begin{array}{c}\text { Independent } \\
t \text { tests }\end{array}$ & Paired $t$ tests \\
\hline Spain & $\begin{array}{l}2.54 \\
(.02)(1,052)\end{array}$ & $\begin{array}{l}2.53 \\
(.02)(580)\end{array}$ & .01 & 1.17 & $\begin{array}{l}1.71^{*} \\
(491)\end{array}$ \\
\hline Hungary & $\begin{array}{l}2.51 \\
(.01)(1,244)\end{array}$ & $\begin{array}{l}2.49 \\
(.01)(722)\end{array}$ & .02 & 0.98 & $\begin{array}{l}1.99^{*} \\
(689)\end{array}$ \\
\hline Greece & $\begin{array}{l}2.40 \\
(.02)(754)\end{array}$ & $\begin{array}{l}1.97 \\
(.04)(355)\end{array}$ & .43 & $8.74^{* * *}$ & $\begin{array}{c}7.16^{* * *} \\
(321)\end{array}$ \\
\hline Chile & $\begin{array}{l}2.48 \\
(.01)(602)\end{array}$ & $\begin{array}{l}2.49 \\
(.02)(322)\end{array}$ & -.01 & 0.52 & $\begin{array}{l}1.11 \\
(269)\end{array}$ \\
\hline Bulgaria & $\begin{array}{l}2.55 \\
(.01)(917)\end{array}$ & $\begin{array}{l}2.32 \\
(.02)(652)\end{array}$ & .23 & $9.13^{* * *}$ & $\begin{array}{c}8.46^{* * *} \\
(577)\end{array}$ \\
\hline Uruguay & $\begin{array}{l}2.52 \\
(.01)(619)\end{array}$ & $\begin{array}{l}2.45 \\
(.05)(207)\end{array}$ & .07 & 1.26 & $\begin{array}{l}1.32^{\#} \\
(177)\end{array}$ \\
\hline U.S. & $\begin{array}{l}5.05 \\
(.06)(1,056)\end{array}$ & $\begin{array}{l}4.83 \\
(.07)(1,057)\end{array}$ & .22 & $2.40^{*}$ & $\begin{array}{c}2.51^{* *} \\
(871)\end{array}$ \\
\hline Hong Kong & $\begin{array}{l}4.98 \\
(.02)(690)\end{array}$ & $\begin{array}{l}4.90 \\
(.04)(572)\end{array}$ & .08 & $1.54^{\#}$ & $\begin{array}{c}0.64 \\
(475)\end{array}$ \\
\hline Japan & $\begin{array}{l}4.90 \\
(.03)(1,202)\end{array}$ & $\begin{array}{l}4.81 \\
(.04)(1,233)\end{array}$ & .09 & $1.86^{*}$ & $\begin{array}{c}1.98^{*} \\
(1,127)\end{array}$ \\
\hline Italy $^{\mathrm{a}}$ & $\begin{array}{l}1.75 \\
(.01)(2,324)\end{array}$ & $\begin{array}{l}1.47 \\
(.02)(1,661)\end{array}$ & .28 & $10.82^{* * *}$ & $\begin{array}{l}9.32^{* * *} \\
(1,594)\end{array}$ \\
\hline $\begin{array}{l}\text { United } \\
\text { Kingdom }^{\mathrm{b}}\end{array}$ & $\begin{array}{l}3.09 \\
(.01)(2,401)\end{array}$ & $\begin{array}{l}2.45 \\
(.02)(1,870)\end{array}$ & .64 & $22.32^{* * *}$ & $\begin{array}{c}20.80^{* * *} \\
(1,612)\end{array}$ \\
\hline
\end{tabular}

Note. Values are mean proximity scores with standard errors and sample sizes. Larger scores suggest more cross-cutting exposure on a 4-point scale for the first set of countries (1-4) and on a 10 -point scale for the second set of countries (0-10).

${ }^{a}$ Means based on left-right placements of the parties that media favor, measured as the absolute distance from the respondents' own left-right placement.

${ }^{\mathrm{b}}$ Means based on a 5-point scale.

${ }^{\#} p<.10 ;{ }^{*} p<.05 ;{ }^{* *} p<.01 ;{ }^{* * *} p<.001$ (one-tailed).

identities, which facilitates selective exposure. We test this hypothesis with countries as the unit of analysis while also examining whether newspapers exhibit higher levels of party parallelism and, as a result, provide an easier path to self-selection, leading to lower levels of cross-cutting exposure.

To facilitate comparisons of cross-cutting exposure among countries, we assign values to each respondent such that newspapers and television news are leaning toward a respondent's own views and producing little cross-cutting exposure (0), not leaning in either direction (1), or leaning away from a respondent's own views and producing relatively 


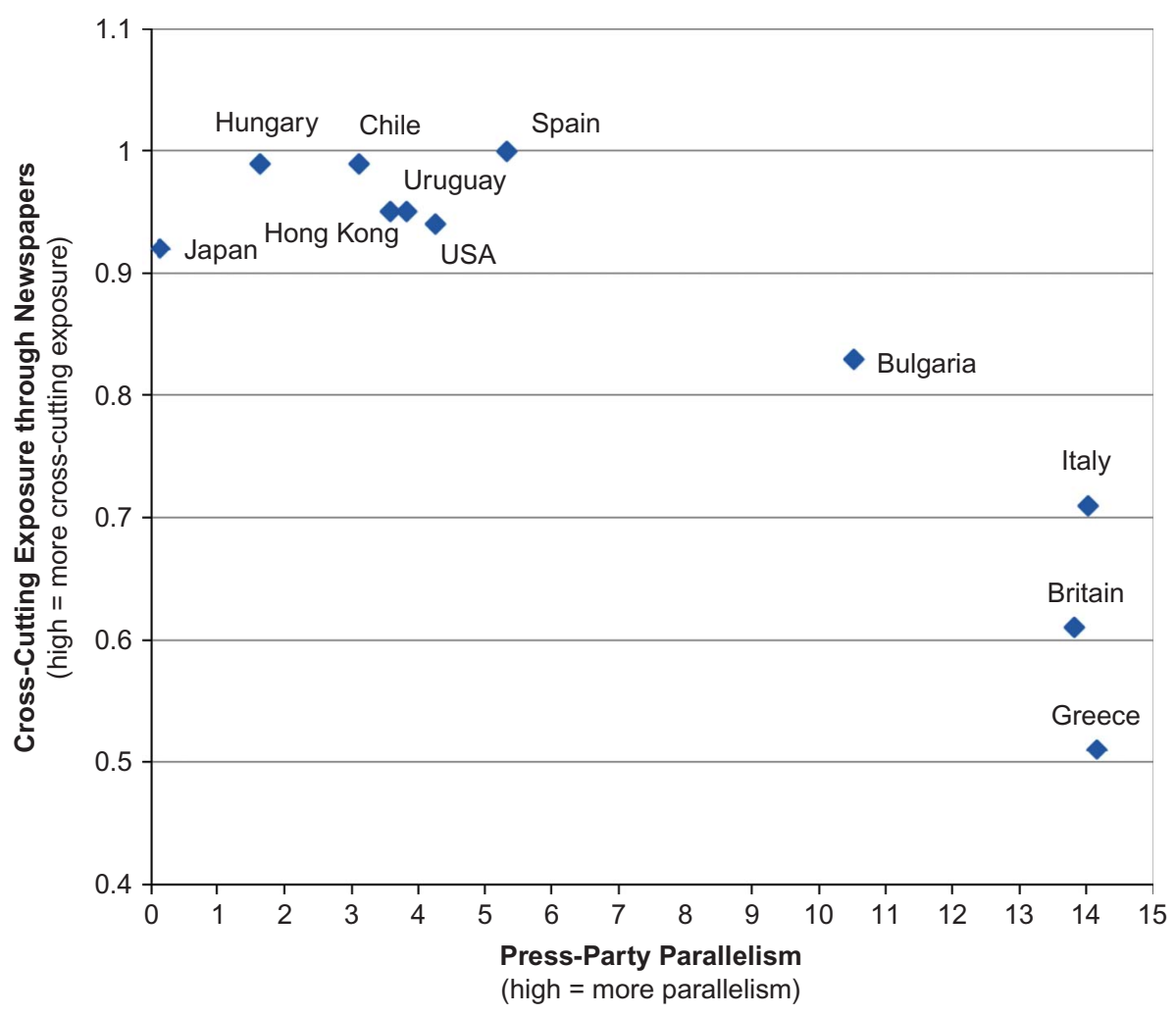

Figure 3. Relationship between press-party parallelism and cross-cutting exposure through newspapers.

high levels of cross-cutting content (2). Figure 3 shows levels of cross-cutting exposure in each country on the $y$-axis and levels of press-party parallelism on the $x$-axis. The relationship is strong and negative: Higher levels of press-party parallelism are associated with lower levels of cross-cutting exposure through respondents' most frequently read newspaper $(r=-.89, p<.001)$. This pattern suggests that when newspaper readership is structured along party lines, it goes hand in hand with low levels of cross-cutting exposure.

Figure 4 shows levels of cross-cutting exposure on the y-axis and levels of televisionparty parallelism on the $x$-axis. As in Figure 3, the relationship in Figure 4 is also negative: Higher levels of TV-party parallelism are associated with lower levels of crosscutting exposure through respondents' most frequently watched television news program $(r=-.90, p<.001)$. But unlike Figure 3, which shows the countries spread out along much of the range of press-party parallelism, Figure 4 shows almost all of the countries clustered at low scores of TV-party parallelism, and the relationship is driven almost entirely by two data points, Greece and Italy.

For both newspapers and television news, higher levels of media-party parallelism are negatively related to cross-cutting exposure within a country. In addition, the difference in levels of media-party parallelism between newspapers and television may help account for the lower levels of cross-cutting exposure through newspapers. Paired $t$ tests revealed significantly lower levels of media-party parallelism for television news than for newspapers 


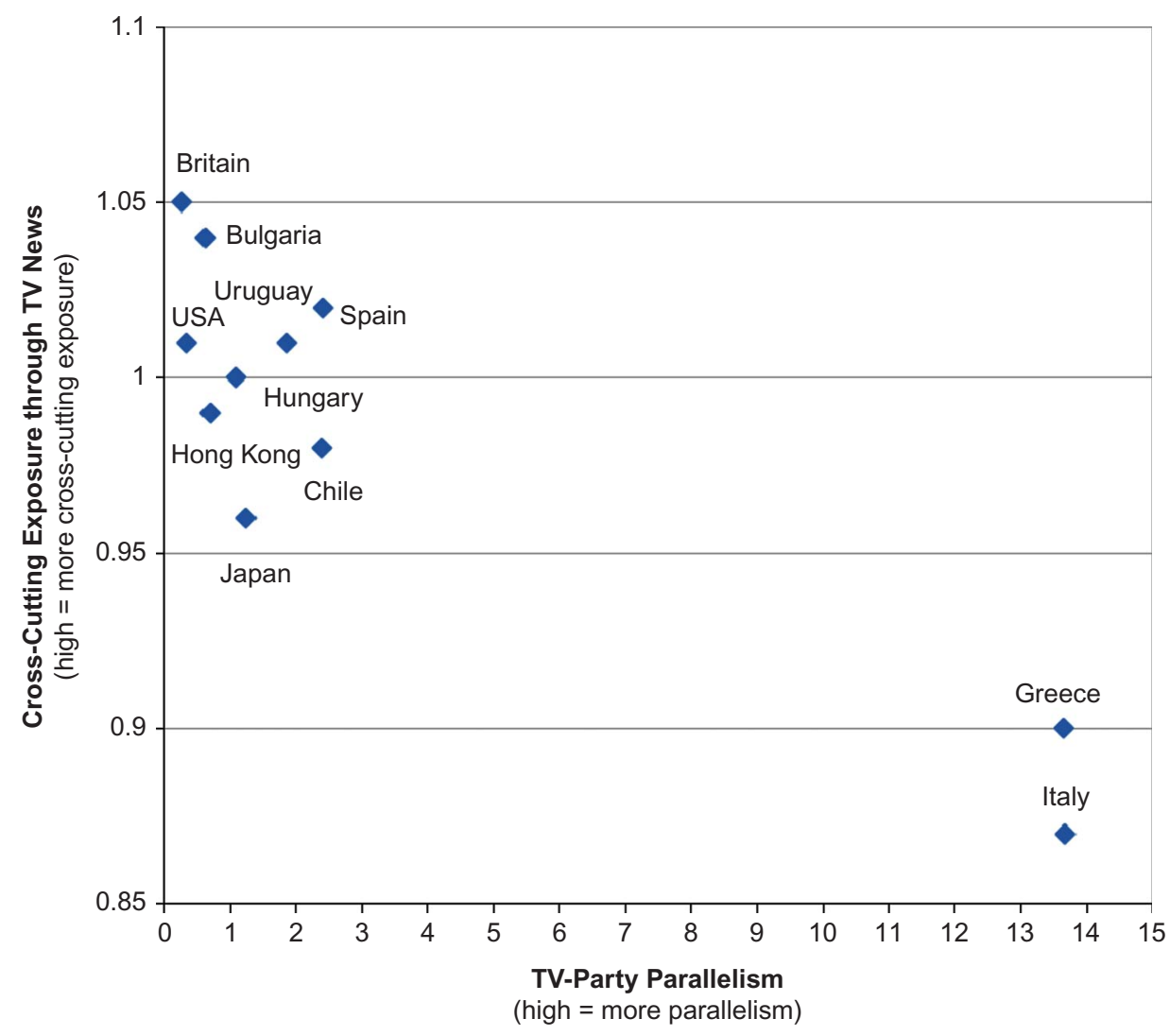

Figure 4. Relationship between TV-party parallelism and cross-cutting exposure through television news.

( $M=6.76$ and 3.48 , respectively, $p<.05$ ). Based on these findings, we argue that newspapers provide less exposure to cross-cutting political ideas than television news because people can more easily choose newspapers that conform to their preexisting political views.

\section{Accounting for National Variations in News Media Use}

Thus far we have characterized each country's extent of mediated cross-cutting exposure by virtue of reports from their newspaper readers and television viewers. This gives us an impression of the extent of cross-cutting exposure among those who watch or read. What this approach ignores is that overall levels of exposure to newspapers and television differ significantly across countries. For example, if newspapers in a given country expose readers to a great many oppositional viewpoints, but only a tiny percentage of the public reads those newspapers, then newspapers within that country cannot do much to advance the overall extent of cross-cutting exposure. In order to simultaneously take into account the proportion of the population using a given source and the extent to which it exposes respondents to views similar to or different from their own political leanings, measures of the extent of exposure to cross-cutting views were weighted by the percentage of the population exposed through a given medium. 


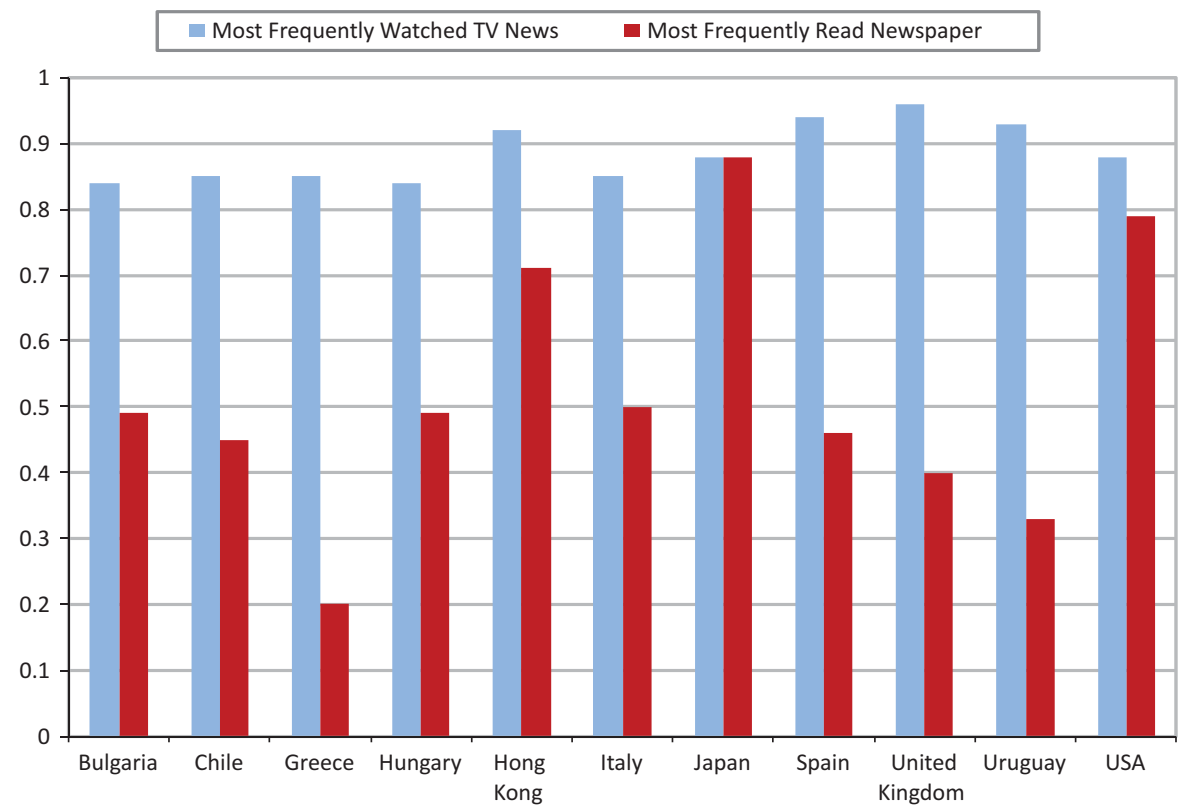

Figure 5. Cross-cutting exposure, weighted by levels of exposure to each media source, by country.

Self-reported news media usage is typically inflated (Price \& Zaller, 1993; Zaller, 2002). Nevertheless, assuming they are inflated roughly equally across all counties, we can make comparisons between frequencies of use by medium. In 10 of the 11 countries there are significantly more users of television news than newspapers, often with large differences between the two $(p<.05)$. Japan is the lone exception, with slightly yet significantly more users of newspapers than television news $(p<.05) .^{5}$

So what happens to our conclusions when we take into account differences in readership and viewership? Figure 5 shows the average levels of cross-cutting exposure weighted by the percentage of the sample in each country that uses newspapers and television news. The results are unambiguous. In every country save one (Japan), there are greater overall levels of cross-cutting exposure produced by television news than by newspapers. The quite modest advantage of television news in extent of cross-cutting exposure (Table 1) receives a substantial boost by taking account of the much higher frequencies of use of television news in general. These findings underscore the practical implications of both the quality and quantity of media exposure.

\section{Discussion}

The fact that strong partisans on opposite sides of a controversy may evaluate the same media content as biased in opposite directions is an important perceptual puzzle, but it is difficult to generalize the implications of hostile media phenomena outside of a controlled setting. In the real world, our findings suggest, partisans on opposite sides of a controversy may not use the same media. When they do, they may differ from opposing partisans in the extent that they perceive favoritism.

Within the United States, our findings also have implications for the apparent trend toward declining confidence and trust in media. The General Social Survey suggests a 
systematic loss in confidence in media in recent years. However, in all documented trends involving decline, respondents were asked about "the media," "the press," "news organizations," and the like. Although pollsters designed these general questions to refer to a few mainstream news sources, it is difficult to know to what respondents are referring when answering these questions in today's media environment. We suspect that if respondents were asked instead about a medium that they themselves use, as in this study, the response trends might look quite different. For most Americans, "the media" now includes sources that are perceived as agreeable, highly disagreeable, and everything in between.

Yet, across all of the countries we studied, people overwhelmingly perceived the television program, and especially the newspaper, that they use most frequently as supportive rather than hostile toward their political views, when they perceived any partisanship at all. Overall, then, the media environment experienced by most citizens is a friendly one. The existence of relative hostile media perceptions should not be misconstrued as evidence of abundant mediated cross-cutting exposure. In fact, most people gravitate toward agreeable sources, resulting in little cross-cutting exposure. Media may, as Mutz and Martin (2001) argue, exceed the extent of cross-cutting exposure via interpersonal sources, but that is not saying a whole lot given the political homogeneity of social networks.

The ability to identify friendly sources is facilitated by high levels of media-party parallelism. When sources are more segregated by their audiences' party affinities, people can more easily exercise selective exposure, as is particularly evident with newspapers. As a result, cross-cutting exposure is especially unlikely in countries with high levels of media-party parallelism. The implications of this finding are problematic; it suggests that countries with more politically diverse media options end up with precisely the opposite of what diversity advocates have in mind. An aggregate media environment can be accurately characterized as diverse, yet it facilitates individuals' abilities to avoid cross-cutting political ideas. This poses a dilemma for theorizing what the ideal media environment should look like.

Although this study is unique in its ability to provide comparable data on so many different countries during the same decade, it nonetheless has limitations. First and foremost, our findings are only as good as our measures of our dependent variable. As described above, these items were constructed from multiple questions asking which party or candidate a given source favors, if any, combined with information on each individual's affinity for different parties. Do these measures of cross-cutting exposure accurately reflect exposure to disagreeable views? Because the beneficial effects of cross-cutting exposure rely upon thoughtful consideration of oppositional views, perceptions of disagreement are more theoretically relevant than actual levels of exposure (Mutz \& Martin, 2001). In studies of political agreement and disagreement in social networks, for example, effects were found to be contingent on perceptions of political agreement/disagreement with discussion partners (Huckfeldt \& Sprague, 1995). To the extent that mediated exposure operates similarly, perceptions are clearly the more appropriate measure. ${ }^{6}$

In fact, even if it were possible, we would be reluctant based on the usual content analysis procedures to label one source as more objective or balanced than another, particularly across international boundaries. Although some sources probably are indeed more partisan than others, given the difficulties that would be involved in developing a reputable measure of what counts as objective coverage, obtaining coders from each country of all possible political perspectives, and so forth, we chose instead to characterize countries along an independent scale of media-party parallelism, tapping the extent to which the structure of the party system is reflected in the structure of media use. Media-party parallelism is 
strongly related to the extent of cross-cutting exposure as measured by the combination of survey questions. ${ }^{7}$

Although the strong correlation between cross-cutting exposure and media-party parallelism helps to validate our measure of cross-cutting exposure, some concerns may surround the decision to categorize those who did not perceive partisanship in their media sources at the midpoint of the scale. One might perceive no partisanship either because the source included very little political content of any stripe or because the source included balanced coverage, that is, equal amounts of congenial and oppositional viewpoints.

If the former were true, then we overestimated the extent of cross-cutting exposure, and this may be especially the case for television news. That is, if commercial television news emphasizes sensationalism/entertainment, then there is not much political content with which to agree or disagree. By contrast, if not perceiving partisanship indicates exposure to balanced coverage, then we may have underestimated the extent of cross-cutting exposure. Both possibilities appear highly unlikely, however, given the results in Figures 1 and 2, which only include those who perceived partisanship. Among those who perceive partisanship, the norm is clearly use of friendly rather than hostile media, particularly in the case of respondents' most frequently read newspaper. Moreover, the same pattern is evident in Table 1, which presents levels of cross-cutting exposure with those who did not perceive partisanship placed at the midpoint of the scale. In other words, regardless of whether we include or exclude those who did not perceive partisanship, our conclusions hold.

By utilizing data from 11 countries, this study also offers highly generalizable evidence for the role of the information environment in facilitating or inhibiting partisan selective exposure and for the dominance of friendly media in people's information environments. This is not a random sample of countries, to be sure, but our study goes far beyond existing single-country studies in establishing the generality of this pattern. ${ }^{8}$

Would the main thrust of our results change if we did not restrict our analyses to respondents' most watched TV news program and most read newspaper? Although we can only speculate, we suspect that the answer to this question is no, largely because relatively few people read more than one newspaper or watch more than one television news program..$^{9}$ Moreover, at least in the 1990s, cable television did not offer as many partisan voices, so even people who did watch multiple television news programs could not easily restrict their exposure to congenial political views. Some of the countries surveyed asked about additional sources, but many did not, thus limiting our ability to address this concern.

Of course, in recent years the number of partisan programs on cable television has expanded substantially. Based on the American experience, we can surmise that changes in technology have continued to expand the availability of sources to most citizens in developed countries since the 1990s, so we would not necessarily expect the same pattern in 2010. Particularly with respect to television, the explosion of channels has meant greater audience fragmentation, which seems unlikely to facilitate greater cross-cutting exposure. So if we were to extrapolate our findings, it would not be in the direction of greater cross-cutting exposure.

Although the theoretical substance of our findings - that more partisan information environments suppress cross-cutting exposure-should be as true today as it was in the 1990s, it may also be true that television news no longer offers an advantage over newspapers in exposing people to oppositional viewpoints. Whereas newspapers, at least in Europe, appear to be moving mostly in the direction of providing less partisan coverage (Hallin \& Mancini, 2004; but see Hallin, 2009, for exceptions), the opposite appears to be occurring with regard to television news (Hallin, 2006). In the U.S., for instance, 
advertisers increasingly segment audiences into ever-smaller "lifestyle" categories—which are linked to, though not mirror images of, political identities (Turow, 1997). Indeed, Nielsen viewership ratings show an incredible degree of fragmentation, as audiences leave television broadcast networks in favor of the varied (and more partisan) menu of content available on cable and satellite channels (Webster, 2005). Moreover, media segmentation is not just an American problem (Katz, 1996).

When scholars call for public discourse to include a diversity of political viewpoints, rarely, if at all, is the distinction made between the diversity of views within information sources, on the one hand, and the diversity of views between information sources, on the other (but see Hallin \& Mancini, 2004). Paradoxically, countries with the most clearly identified differences between information sources produce the least amount of cross-cutting exposure for their citizenry, likely owing to the greater ease with which people can exercise partisan selective exposure. This problem is likely to be exacerbated in the years ahead, as media choice continues to expand through cable and satellite television, as well as the Internet. The trouble, of course, is how to square the democratic necessity of exposing citizens to oppositional viewpoints with most people's desire to seek out content that best matches their social lifestyles and political identities.

Although we focused on leveraging cross-national variation in media systems, this variation carries important implications for comparative media studies as well. Of perhaps most interest, our results complicate efforts to formulate typologies of media systems that map onto geographic regions (Hallin \& Mancini, 2004). Interestingly, in the case of television news, there was very little variation between countries, at least as of the 1990s. Nor was there much difference in overall levels of exposure to television news between countries. However, we found a great deal of variation between the extent and direction of perceived partisanship for respondents' most read newspaper and in overall levels of exposure to newspapers. Along similar lines, we found few differences in TV-party parallelism, but substantial variation in press-party parallelism. This variation does not strictly follow geographic patterns, thus leaving unknown what underlying factors produce media systems with more or less cross-cutting exposure (but see Hallin \& Mancini, 2004).

It also remains largely unknown just what effects mediated cross-cutting exposure has on audiences. To the extent that it mirrors the effects of personal networks, it may be a deterrent to participation while simultaneously serving as a boon to tolerance for differing political perspectives (Mutz, 2002a, 2002b). Empirical evidence for negative effects of mediated cross-cutting exposure on political participation has been mixed, however. European nations with less media-party parallelism-and, by implication, more crosscutting exposure at the individual level-had lower levels of voter turnout (van Kempen, 2007), while a much larger and more varied sample of countries revealed no association between the partisanship of a country's newspapers and voter turnout (Baek, 2009). If the effects of cross-cutting exposure via mass media do, in fact, produce results parallel to interpersonal communication, then television news appears more amenable to the goals of deliberative democracy, whereas newspapers are better suited to the goals of participatory democracy, at least as of the 1990s when these data were collected.

Our observations beg the question of what, specifically, the many advocates of diverse voices had in mind. Is the ideal information environment for democracy one that maximizes the aggregate diversity of ideas or one that maximizes intra-individual exposure to diverse ideas? As our results demonstrate, these two goals are not met by the same information environment. Media that include a breadth of ideas or "voices" is an admirable principle, and yet there is a great deal of ambiguity as to what this principle requires in practice. Many promote the availability of politically diverse sources, yet expect those same conditions to 
produce exposure to diverse ideas at the intra-individual level. For example, regulations on ownership of media outlets appear to rest on the assumption that aggregate diversity will promote a marketplace of ideas. In addition, the mere idea that the partisan press of old promoted political debate in the U.S. implies that citizens were hearing both sides, albeit through different newspapers. In most discussions of principle and practice this distinction has been glossed over, assuming that if a society produces one form of diversity it also produces the other.

And yet if one considers some of the functions that the multitude of voices are said to serve, they point very clearly to the importance of intra-individual exposure to a diversity of ideas. Consider, for example, the well-known assertion that a free press functions to allow society to blow off steam, and thus helps preserve civil life (e.g., Emerson, 1970; Meiklejohn, 1965): “The opposition is indispensable. A good statesman, like any other sensible human being, always learns more from his opponents than from his fervent supporters" (Lippmann, 1939). A media environment of diverse, strongly partisan voices seems unlikely to achieve that end if these voices preach solely to the choir. In fact, they might inadvertently end up serving a rabble-rousing function instead. But to the extent that intra-individual exposure to diverse voices is encouraged by a given media environment, a more civil political life seems entirely likely.

\section{Notes}

1. Although the subtleties of translation from the original survey languages of the CNEP studies are beyond our personal expertise, it is worth noting that in most of the English translations of these questions (see Appendix A), the terms "favor," "support," or "give priority to" a party or candidate were used. Further evidence that these measures are tapping perceived partisanship rather than perceived bias comes from the data themselves, as shown in later analyses. If these items tapped accusations of bias, then one would expect them to come primarily from those on the opposite side of the political spectrum. For example, in the U.S., Republicans would claim television news favored Democrats, and Democrats would claim it favored Republicans.

2. Following van Kempen (2007), we used the results of the most recent national election in each country to approximate the size of each political party (i.e., percentage of votes going to each party).

3. Like van Kempen (2007), separate media-party parallelism scores were calculated for newspapers and television news, with scores ranging from 0 to 100 (higher scores indicating more parallelism). Because we relied on different surveys than van Kempen, however, our measures of party preferences and media use differed slightly from hers. To measure party preferences, we relied on the same items we used to calculate levels of cross-cutting exposure, that is, how close to or distant from a major political party one feels. And to measure exposure to specific newspapers and television news programs, we used the newspaper or television news program that respondents watched or read most frequently. Unlike van Kempen, we did not limit the media sources to those used "regularly," which she defined as sources that at least $5 \%$ of the sample used at least 1 day a week. The measures of frequency of media use in many of the CNEP countries did not distinguish between those who used a source 1 day a week or less. Moreover, some countries are dominated by local and regional newspapers. In the U.S., for instance, the CNEP survey showed that not a single newspaper was read by $5 \%$ of the sample.

4. In the case of Hong Kong, however, the marginally significant difference between television news and newspapers using the independent samples $t$ test was not marginally significant using the paired $t$ test $(p<.10$ and $p>.10$, respectively).

5. The percentages of the samples that watch TV news and/or read a newspaper are as follows: $81 \%$ and $59 \%$ (Bulgaria), $87 \%$ and $45 \%$ (Chile), $94 \%$ and $40 \%$ (Greece), $84 \%$ and $49 \%$ (Hungary), 93\% and 75\% (Hong Kong), 98\% and 71\% (Italy), 92\% and 96\% (Japan), 92\% and 46\% (Spain), 
91\% and 66\% (United Kingdom), $92 \%$ and $35 \%$ (Uruguay), and $87 \%$ and $84 \%$ (U.S.). To compare the proportions of respondents who watch TV news and/or read a newspaper, we used McNemar tests, which assess differences of proportions for matched pairs.

6. Moreover, perceptions and content analysis have produced the same pattern of results (Mutz \& Martin, 2001).

7. Although we examined media-party parallelism because it has the clearest connection to cross-cutting exposure, other aspects of media systems, such as the extent of media commercialization, may be influential as well.

8. It would, of course, be interesting to extend the analyses to other countries. Take, for example, a country with simultaneously high levels of newspaper readership and media-party parallelism. On the one hand, as one reviewer noted, this type of media environment might encourage people to read both newspapers that conform to their political views and newspapers with which they disagree. But on the other hand, people might simply read a greater number of like-minded newspapers, as predicted by theories of selective exposure.

9. As of when these data were collected, the number of people reading more than one newspaper was not enough to overturn the general pattern we observed even if the second sources were not as like-minded. Moreover, the pattern is much as it is for those with multiple political discussants (see Mutz, 2006); additional discussants are less likely to be as like-minded as the ones the respondent talks to most frequently, but because only highly political strong partisans use multiple sources, the aggregate advantage of these weaker ties is not realized. Users of multiple political media are especially likely to care about politics and to seek out political agreement.

\section{References}

Baek, M. (2009). A comparative analysis of political communication systems and voter turnout. American Journal of Political Science, 53, 376-393.

Barber, B. (1984). Strong democracy: Participatory politics of a new age. Berkeley: University of California Press.

Blais, A., Gidengil, E., Nadeau, R., \& Nevitte, N. (2001). Measuring party identification: Britain, Canada, and the United States. Political Behavior, 23, 5-22.

Calhoun, C. (1988). Populist politics, communications media and large scale societal integration. Sociological Theory, 6, 219-241.

Cotton, J. L. (1985). Cognitive dissonance in selective exposure. In D. Zillmann \& J. Bryant (Eds.), Selective exposure to communication (pp. 11-33). Hillsdale, NJ: Erlbaum.

Dalton, R. J., Beck, P. A., \& Huckfeldt, R. (1998). Partisan cues and the media: Information flows in the 1992 presidential election. American Political Science Review, 92, 111-126.

Emerson, T. (1970). The system of freedom of expression. New York, NY: Vintage.

Eveland, W. P., Jr., \& Shah, D. (2003). The impact of individual and interpersonal factors on perceived news media bias. Political Psychology, 24, 101-117.

Frey, D. (1986). Recent research on selective exposure to information. In L. Berkowitz (Ed.), Advances in experimental social psychology (Vol. 19, pp. 41-80). New York, NY: Academic Press.

Gunther, A. C. (1992). Biased press or biased public? Attitudes toward media coverage of social groups. Public Opinion Quarterly, 56, 147-167.

Gunther, A. C., \& Christen, C. T. (2002). Projection or persuasive press? Contrary effects of personal opinion and perceived news coverage on estimates of public opinion. Journal of Communication, 52, 177-195.

Hallin, D. C. (2006). The passing of the high modernism of American journalism: Revisited. Political Communication Reports, 16, 1. Retrieved from http://frank.mtsu.edu/ pcr/1601_2005_winter/ commentary_hallin.htm

Hallin, D. C. (2009). Not the end of journalism history. Journalism, 10, 332-334. 
Hallin, D. C., \& Mancini, P. (2004). Comparing media systems. New York, NY: Cambridge University Press.

Huckfeldt, R., \& Sprague, J. (1995). Citizens, politics, and social communication: Information and influence in an election campaign. New York, NY: Cambridge University Press.

Iyengar, S., \& Hahn, K. S. (2009). Red media, blue media: Evidence of ideological selectivity in media use. Journal of Communication, 59, 19-39.

Iyengar, S., Hahn, K. S., Krosnick, J. A., \& Walker, J. (2008). Selective exposure to campaign communication: The role of anticipated agreement and issue public membership. Journal of Politics, $70,186-200$.

Johnston, R. (2006). Party identification: Unmoved mover or sum of preferences? Annual Review of Political Science, 9, 329-351.

Katz, E. (1996). And deliver us from segmentation. Annals of the American Academy of Political and Social Science, 546, 22-33.

Lazarsfeld, P. F., Berelson, B., \& Gaudet, M. (1944). The people's choice. New York, NY: Duell, Sloan, and Pearce.

Lippmann, W. (1939, August). The indispensable opposition. Atlantic Monthly, 186.

Meffert, M. F., Chung, S., Joiner, A. J., Waks, L., \& Garst, J. (2006). The effects of negativity and motivated information processing during a political campaign. Journal of Communication, 56, 27-51.

Meiklejohn, A. (1965). Free speech and its relation to self-government. New York, NY: Harper \& Brothers.

Mill, J. S. (1956). On liberty (C. V. Shields, Ed.). Indianapolis, IN: Bobbs-Merril. (Original work published 1859)

Mutz, D. C. (2002a). The consequences of cross-cutting networks for political participation. American Journal of Political Science, 46, 838-855.

Mutz, D. C. (2002b). Cross-cutting social networks: Testing democratic theory in practice. American Political Science Review, 96, 111-126.

Mutz, D. C. (2006). Hearing the other side: Deliberative versus participatory democracy. New York, NY: Cambridge University Press.

Mutz, D. C., \& Martin, P. S. (2001). Facilitating communication across lines of political difference: The role of mass media. American Political Science Review, 95, 97-114.

Price, V., \& Zaller, J. (1993). Who gets the news? Alternative measures of news reception and their implications for research. Public Opinion Quarterly, 57, 133-164.

Schudson, M. (1981). Discovering the news. New York, NY: Basic Books.

Sears, D. O., \& Freedman, J. L. (1967). Selective exposure to information: A critical review. Public Opinion Quarterly, 31, 194-213.

Seymour-Ure, C. (1974). The political impact of mass media. London, England: Constable.

Turow, J. (1997). Breaking up America. Chicago, IL: University of Chicago Press.

Vallone, R. P., Ross, L., \& Lepper, M. R. (1985). The hostile media phenomenon: Biased perception and perceptions of media bias in coverage of the Beirut massacre. Journal of Personality and Social Psychology, 49, 577-585.

van Kempen, H. (2007). Media-party parallelism and its effects: A cross-national comparative study. Political Communication, 24, 303-320.

Webster, J. G. (2005). Beneath the veneer of fragmentation: Television audience polarization in a multichannel world. Journal of Communication, 55, 366-382.

Young, I. M. (1996). Communication and the Other: Beyond deliberative democracy. In S. Benhabib (Ed.), Democracy and difference (pp. 120-136). Princeton, NJ: Princeton University Press.

Zaller, J. (2002). The statistical power of election studies to detect media exposure effects in political campaigns. Electoral Studies, 21, 297-329. 


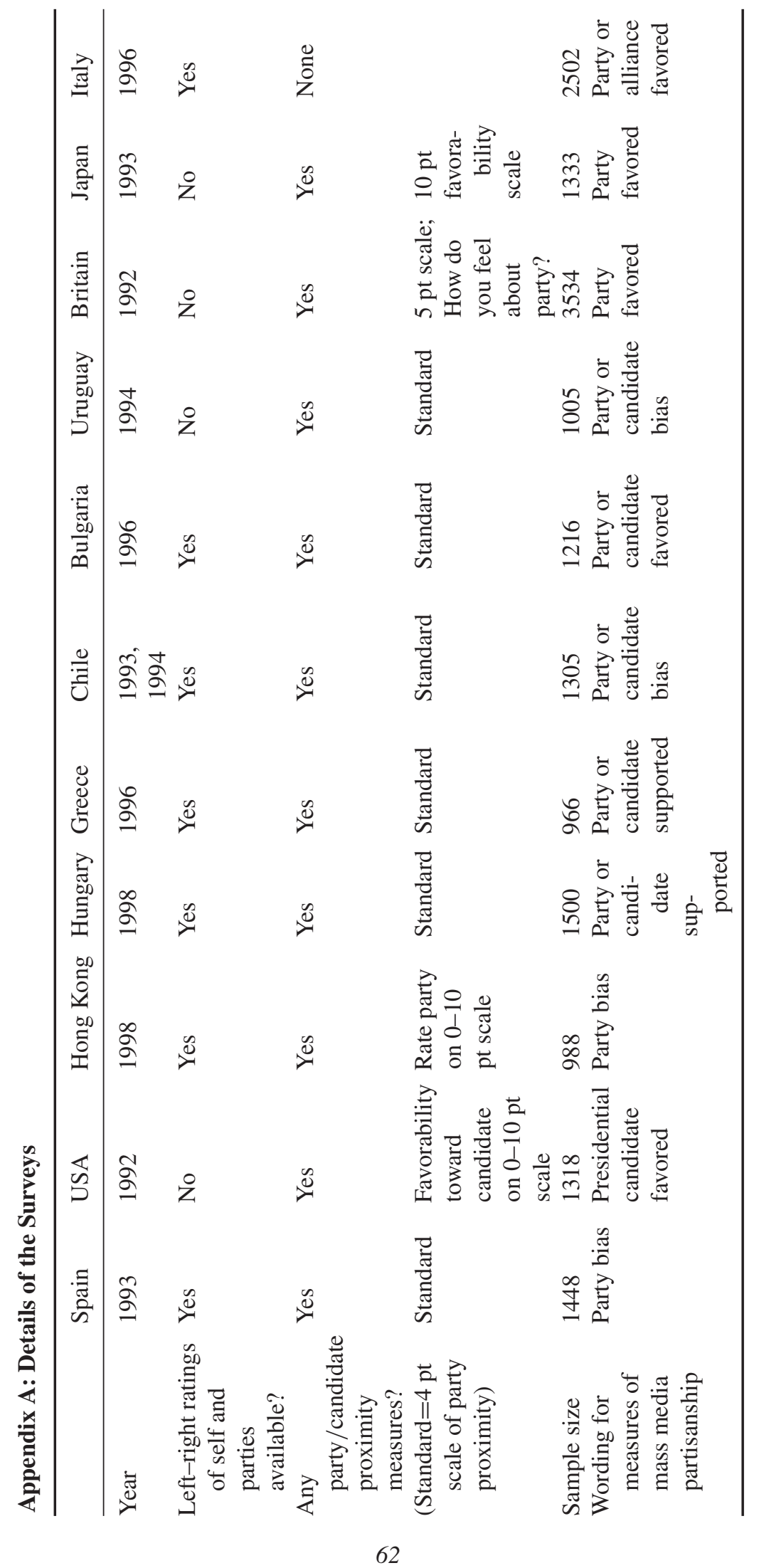




\section{Appendix B: Wording of the Survey Items (English Translations)}

\section{Uruguay}

During the past electoral campaign, which newspaper did you read most often? (openended) Did you read any other newspaper? Which one? On average, how many days a week did you read the first newspaper? Do you think any of these newspapers were biased towards a particular party or candidate? To which party or candidate? [read newspaper 1].

During the past election campaign, did you watch a television news broadcast? Which news broadcast? Any others? Could you tell me which network broadcast showed this news broadcast? How many days a week did you watch the news on this network? Do you think it favored a particular political party or candidate? Which party or candidate?

Could you please tell me to what degree you feel close to or distant from each of the main political parties in Uruguay? (very close, somewhat close, rather distant, very distant).

\section{Spain}

During the past electoral campaign, which newspaper did you read most often? On average, how many days a week did you read the first newspaper? Do you think any of these newspapers were biased towards a particular political party or candidate? To which party? [read newspaper 1].

During the past election campaign, did you watch a television broadcast? Which news broadcast? Could you tell me which network broadcast this news show? How many days a week did you watch the news on this network? Do you think it favored a particular political party or candidate? Which party?

Could you please tell me to what degree you feel close to or distant from each of the main political parties in Spain? (very close, somewhat close, rather distant, very distant).

\section{Japan}

First, did you read a daily newspaper? This is the list of newspapers. What is the name of the daily newspaper you read most? In a normal week, how many days did you read each newspaper? In the national election coming up soon, which parties do you think the newspaper that you read most favored?

In a normal week, how many days did you watch the following news show and local news of TV networks? (5 programs listed: 1 day a week, 2-3 days a week, 4-5 days a week, 6-7 days a week, didn't watch). On the election campaign, which candidates do you think the programs most favored?

I'd like to get your feelings toward the parties by asking you to rate each one on a scale that runs from 0 to 10.10 means you feel most favorable toward the party, 0 means you feel most unfavorable toward the party, and 5 means you feel neutral toward the party.

\section{Hungary}

Which daily paper did you read most frequently? How frequently did you read the paper? (every day or almost every day; weekly, several times; weekly, a few times; less frequently). Did you have the impression that this paper supported any of the parties or candidates in 
the course of the election campaign? Which party, or the candidate of which party, did it support (primarily)?

Which television channel did you see most frequently? How frequently did you see television? (every day or almost every day; weekly, several times; weekly, a few times; less frequently). Did you have the impression that this television supported any of the parties or candidates in the course of the election campaign? Which party, or the candidate of which party, did it support (primarily)?

To what extent are the following political parties close to you? How would you rate them: very close, close, far, or very far?

\section{Hong Kong}

During the past electoral campaign, did you follow the news in the newspapers? Which newspaper did you read most often? On average, how many days a week did you read the [newspaper 1]? Do you think that, in general, the [newspaper 1] was biased towards a particular political party or candidate? To which party or candidate?

During the last election campaign, did you watch the news on the TV? Which station did you watch most often? On average, how many days a week did you watch [station 1]? Do you think that, in general, the [station 1] was biased towards a particular political party or candidate? To which party or candidate?

I'd like to know what you think about each of our political parties. After I read the name of a political party, please rate it on a scale from 0 to 10 , where 0 means you strongly dislike that party and 10 means that you strongly like that party. If I come to a party you haven't heard of or you feel you do not know enough about, just say so.

\section{Bulgaria}

During the past electoral campaign, which newspaper did you read most often? On average, how many days a week did you read the first newspaper? Do you think any of these newspapers were biased towards a particular political party or candidate? Toward which candidate? [read newspaper 1].

During the electoral campaign, did you watch a news broadcast on TV? Which news broadcast did you watch at what time? [Write under news broadcast 1]. Any others? [Write under news broadcast 2 and news broadcast 3]. On which TV channel did you watch [this news broadcast]? [news broadcasts 1, 2, and 3]. How many days during the electoral campaign did you watch the news on [this (these) channel(s)]? [news broadcasts 1, 2, and 3]. Do you think that this TV channel favored a particular political party or candidate? Which candidate? [news broadcasts 1,2 , and 3].

How close do you feel to the following parties? (very close, somewhat close, distant, very distant).

\section{Italy}

During the election campaign, in which newspaper did you read articles about politics? How frequently did you read the newspaper? (less than once a week, 1-2 days a week, 3-4 days a week, every day). Did you have the impression that the newspaper in which you read articles about politics favored one of the political parties or alliances? Which one?

During the election campaign, did you happen to see any TV news programs? Which TV news program did you see most frequently in this period? How often did you see this 
TV news program? (less than once a week, 1-2 days a week, 3-4 days a week, every day). Did you have the impression that the TV news program which you saw favored one of the political parties or alliances? Which one?

Lots of people use the terms "left" and "right" when they talk or think about politics. Think about your political opinions, where would you place yourself: left, center-left, center, center-right, or right?

Lots of people speak about parties in terms of "left" and "right." How would you describe the political orientation of the following parties? For example, where would you place Forza Italia: left, center-left, center, center-right, or right?

\section{United Kingdom}

Do you regularly read one or more daily morning newspapers? Which daily morning newspaper do you read most often? How often do you read [newspaper read most often]? (1 day a week or less, 2 or 3 days a week, 4 or 5 days a week, every day). Which political party did [newspaper read most often] favor in this election?

How often do you watch/listen to the following television/radio news program: [name of program]? (never, one day a week or less often, 2-3 days a week, 4 or more days a week, don't know).

How do you feel about the [name] Party? (strongly in favor, in favor, neither in favor nor against, against, strongly against, don't know).

\section{Chile}

During the electoral campaign, how frequently did you follow political news through ... newspapers, magazines, TV, radio? (every day or almost every day, 3-4 days a week, 1-2 days a week, less frequently, never or almost never). During the past electoral campaign, which newspaper did you read most often? On average, how many days a week did you read the first newspaper? Do you think newspaper \#1 was biased towards a particular political party or candidate? To which party or candidate?

During the past election campaign, did you watch a television news broadcast? Which news broadcast? Any others? Another one? Could you tell me which network broadcast showed this news broadcast? [news broadcasts 1, 2, and 3]. How many days a week did you watch the news on this network? [news broadcasts 1, 2, and 3]. Do you think it [news broadcasts 1, 2, and 3] favored a particular political party or candidate? Which party or candidate?

Could you please tell me to what degree you feel close to or distant from each of the main political parties in Chile? (very close, somewhat close, rather distant, very distant).

\section{Greece}

During the electoral campaign, how frequently did you follow political news through . . . newspapers, radio, TV? (every day or almost every day, 3-4 days a week, 1-2 days a week, less frequently, never or almost never). During the past electoral campaign, which newspaper did you read most often? On average, how many days a week did you read the first newspaper? Do you think any of these newspapers were biased towards a particular political party or candidate? To which party? [Read newspaper 1]. 
During the past election campaign, did you watch a television news broadcast? Which news broadcast? Any others? How many days a week did you watch the news on this network? [news broadcasts 1, 2, and 3]. Do you think it favored a particular party or candidate? Which party?

Could you please tell me to what degree you feel close to or distant from each of the main political parties in Greece? (very close, somewhat close, rather distant, very distant).

\section{United States}

During a normal week, did you read one or more daily newspapers? What is the name of the newspaper? Which presidential candidate do you think the [1st PAPER] favored during the campaign, or didn't it favor any candidate?

In a normal week, did you watch any national network evening news show on TV? In a normal week during the campaign, how many days did you watch [fill TV1]? Which presidential candidate do you think [TV1] favored during the election campaign, or didn't it favor any candidate?

I'd like to get your feelings toward the major candidates for president by asking you to rate each one on a scale that runs from 0 to 10 . Zero means you feel most unfavorable toward the candidate, 10 means you feel most favorable toward the candidate, and 5 means you feel neutral toward the candidate. Using any number from 0 to 10 , overall how unfavorable or favorable do you feel toward Bush? On the same 0 to 10 scale, how unfavorable or favorable do you feel toward Clinton? Using the same 0 to 10 scale, how unfavorable or favorable do you feel toward Perot? 